\author{
تأثير طرائق الري ومغنطة المياه في نمو وحاصل زهرة الشمس وكفاءة استعمال الماء

$$
\begin{aligned}
& \text { محمد مبارك علي عبد الرناق } \\
& \text { أستاذ مساعد }
\end{aligned}
$$ \\ قسم المحاصيل الحقلية - كلية الزراعة - جامعة بغداد \\ * شيماء حسن يحيى \\ الباحث \\ وزارة الزراعة - دائرة الغابات والتصحر
}

Shama.yahya@yahoo.com

المستخلص

نفذت تجرية حقلية خلال الموسمين الربيعيين 2012 و2013 في حقل تجارب قسم المحاصيل الحقلية - كلية الزراعة - جامعة بغداد، بهدف معرفة استجابة محصول زهرة الشمس لطرائق الري وتقانة مغنطة مياه الري في صفات نمو وحاصل زهرة الثمس صنف اقمار وكفاعة استعمال الماء. طبقت التجربة بترتيب الألواح المنشقة على وفق تصميم القطاعات الكاملة المشاة مCBD بثلاثة مكررات. تضمنت الدراسة أريع طرائق للري وهي الري المروز (إ) (القياس) والري التبادلي المتغير (I)

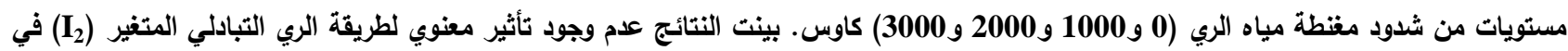

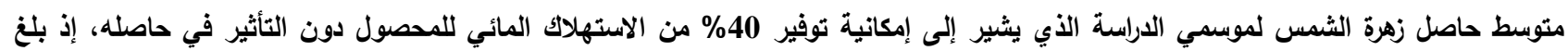

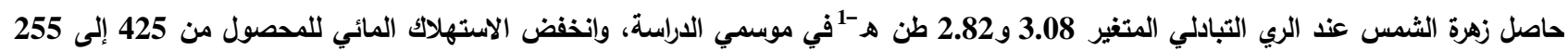

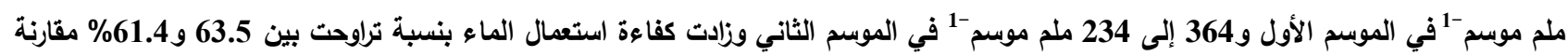
بالري الكامل وزاد الوزن الجاف للمجموع الجذري بنسبة تراوحت بين 4.8 و7.5\% للموسمين بالتتابع، كما اشارت النتائج إلى عدم وجود فروق في

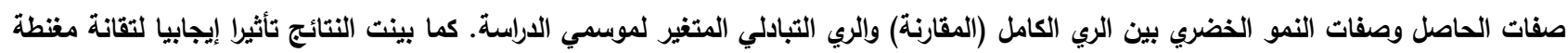

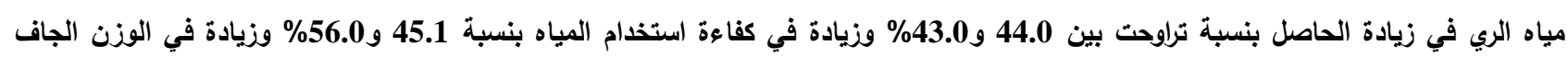

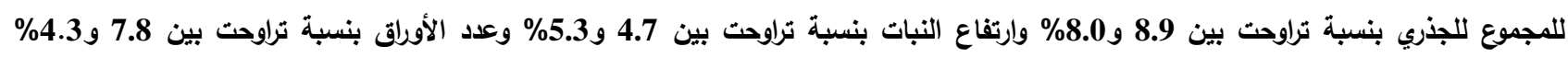

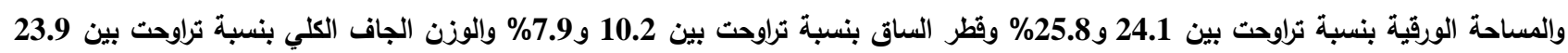
و18.6\% للموسمين بالتتابع. كان التداخل معنويا بين عاملي الاراسة في بعض الصفات المدروسة. الكلمات المفتاحية: النمو الخضري، حاصل البذور، كفاءة استعمال الماء. باء. "البحث مستل من رسالة ماجستير للباحث الأول.

The Iraqi Journal of Agricultural Sciences -930-940: (4) 48/ $2017 \quad$ Yahya \& Abdul-Razaq

\title{
THE EFFECT OF IRRIGATION METHODS AND MAGNETIZATION OF WATER ON GROWTH AND YIELD OF SUNFLOWER AND WATER USE EFFICIENCY
}

${ }^{1}$ Sh. H. Yahya*

Researcher

1.Minist. Prof.

${ }^{1}$ Ministry of Agric. - State of Forest and Desertification

${ }^{2}$ Dept. of Field Crops - Coll. of Agric. - Univ. of Baghdad

Shama.yahya@yahoo.com

\section{ABSTRACT}

This experiment was carried out at the experimental farm of Field Crop Department, College of Agriculture, university of Baghdad, during two spring seasons of 2012 and 2013 to study the response of sunflower cultivar Akmar to irrigation methods, magnetized water technology on growth characteristics, yield and water use efficiency. The experiment was laid out as a split plot in randomized complete block design with three replications. Four irrigation methods were used as main plots, [farrow irrigation $\left(I_{1}\right)$, unfixed alternate furrow irrigation $\left(I_{2}\right)$, fixed alternate furrow irrigation $\left(I_{3}\right)$ and basin irrigation $\left(I_{4}\right)$ ], while four levels of magnetized water $(0,1000,2000$ and 3000) Gauss were used as sub plot treatments. Results revealed that unfixed alternate furrow irrigation method $\left(I_{2}\right)$ did not increase the yield and growth of sunflower for both seasons but it reduces irrigation water by $40 \%$. Yield reached 3.08 and 2.82 ton ha $^{-1}$ in the two seasons respectively, were as irrigation water reduced from 425 to $255 \mathrm{~mm}$ per season in 2012 season and reduced from 364 to 234 mm per season in $2013^{\text {th }}$ season were an increment of water use efficiency (WUE) by $63.5 \%$ and $61.4 \%$ during growing seasons respectively in comparison with full irrigation treatment $\left(I_{1}\right)$. Root dry weight was increased by 4.8 and $7.5 \%$. Results displayed a positive effect of using magnetized irrigation water on all measured traits. Yield was increased by 44.0 to $43.0 \%$, WUE increased by 45.1 to $56.0 \%$, root dry weight by 8.9 and $8.0 \%$, plant height by 4.7 and $5.3 \%$, number of leaves per plant increased by 7.8 to $4.3 \%$, leaf area by $24.1 \%$ to $25.8 \%$, stem diameter by 10.2 to $7.9 \%$ and total dry weight by 23.9 to $18.6 \%$ for both spring seasons of 2012 and 2013 respectively. Interaction relations between experiment treatments were significant in some of studded traits.

Key words: vegetative growth, seed yield, WUE.

* Part of M.Sc. thesis of the first auther. 
بين الموارد المتاحة والطلب المتتامي على المياه، واداركا لهذه

المشكلة الأنية والمستقبلية اقتضى العمل على توفير إدارة جيدة لمياه الري باستخدام تقنيات وطرائق من شأنها رفع يعد محصول زهرة الثمس .Helianthus annuus L من المحاصيل الاقتصادية المهمة في العالم لقصر مدة نمـوه ومردوده الاقتصادي العالي ولاحتواء بذوره على نسبة عالية

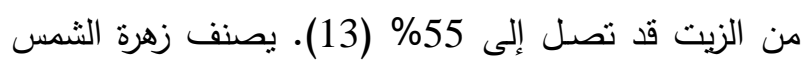

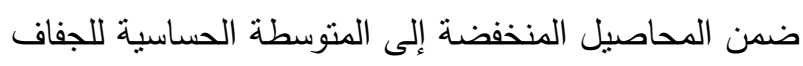
(11)، ويتحمل مدى واسعا من الظروف البيئية القاسية لما

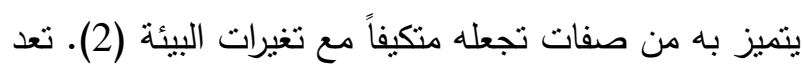

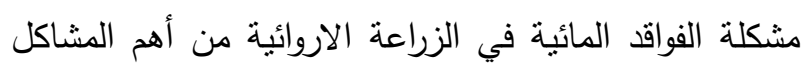

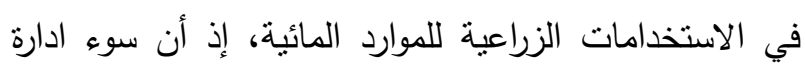
نظام الزراعة المروية ولاسيما فيما بتعلق بمياه الري قد يسهم

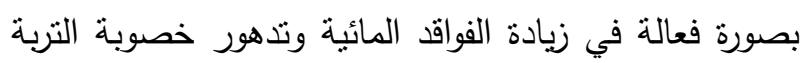

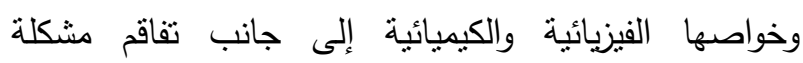
الصرف. إن الموقع الجغرافي للعراق وطبيعة مناخه الجاف وشبه الجاف فضلا عن قلة سقوط الأمطار، وكون القطاع الزراعي يعد أكبر القطاعات استهلاكا للمياه والذي يشكل ما

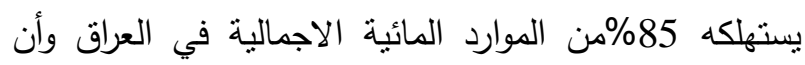
العراق أكثر تضررا بالسياسة المائية من دول الجوار لحاجته

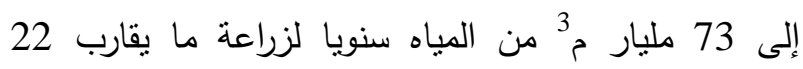

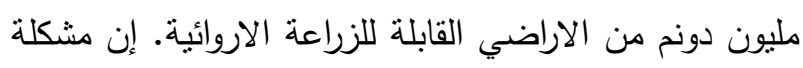
المياه في العراق تعد إحدى المشكلات المهمة والحيوية التي لالي تتطلب جهودا حثيثة واستثنائية لحلها أو التقليل من حدتها بعد التعاه قصور الكميات المتاحة من الواردات المائي خلال الاعوام

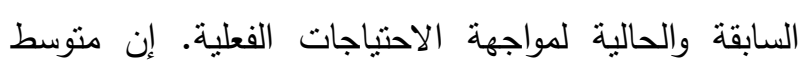
المساحات المزروعة للمدة من 1980-2001 بلغت 7.182 مليون دونم تمثل 38.6\% من صافي المساحات الزراعية المكن ارواؤها التي بلغ مجموع احتباجاتها المائية 37.3

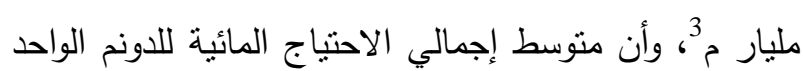

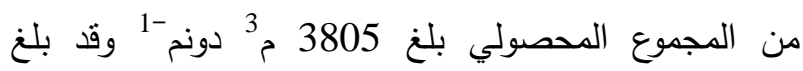

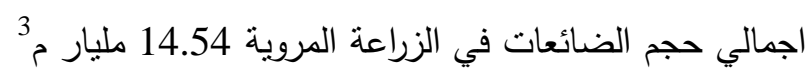
خلال المدة ذاتها، وأن ضياع مليار منز مكعب من المياه

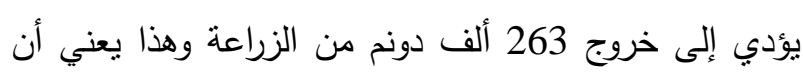
المياه الضائعة يمكن استغلالها في ارواء 3879 ألف دون دونم إضافي وهذا ما يدعونا إلى بذل المزيد من الجهود ووضع الجياه

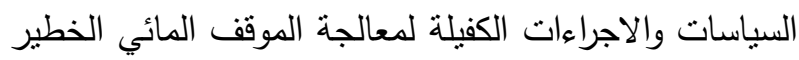
(1). لذا فإن الهدف الذي ينشده العراق هو تحقيق التوازن 
قطر فتحاته 2 ملم والمحتوى الرطوبي عند الثدود (153) و100 و500 و و1000 و 1500) كيلو باسكال لتقدير سعة ولنة

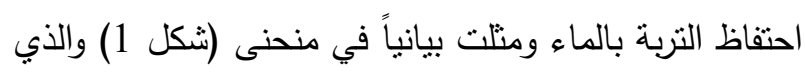
قابلته الرطوبة الحجمية النقطة التي بدأت من 0.31 إلى بلى

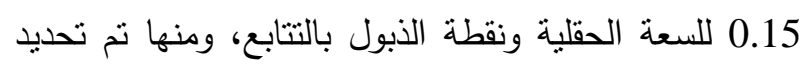
الماء الجاهز في التربة من الفرق بينهما. قياس المحتوى الرطويب للتربة

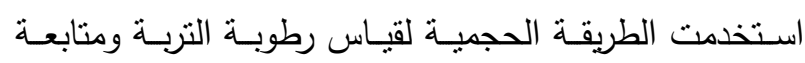
التغيرات الرطوبية في التربة وتحديد وقت الارواء بأخذ نماذج

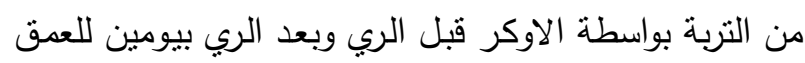

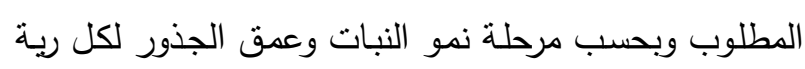

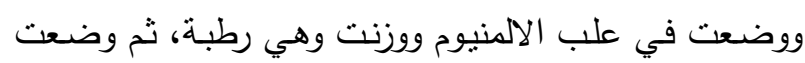
في فرن (Microwave Oven) ولمدة اثنتي عشرة دقيقة

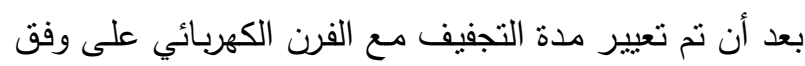

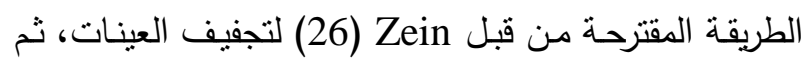
وزنت وقدر المحتوى الرطوبي فيها بحسب المعادلة الواردة في في لمني

:(9) Hillel

$$
\mathrm{p} w=\left(\frac{M s w-M s}{M s}\right) 100
$$

Pw

Msw Ms

طريقة الري

نم الري بأنابيب بلاستيكية مرنة مربوطة بمضخة مثبنة على لى

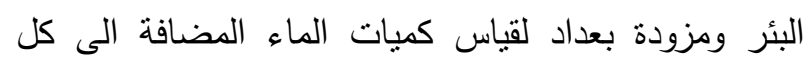

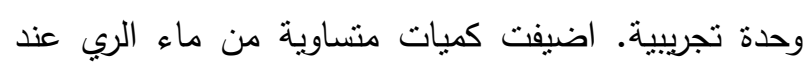
الزراعة الى السعة الحقلية لضمان البزوغ، ثم رويت النباتات عند استتزاف 50\% من الماء الجاهز وبحسب معادلة كمان Kohnke

$$
\text { كما مبين في جدول } 1 .
$$

$$
W=a \cdot A s\left(\frac{\% P w^{F c}-\% P w^{w}}{100}\right) \times \frac{D}{100}
$$

إذ أن: W = حجم الماء الواجب إضافته خلال رية (م²). = a As
المواد والطرائق

نفذت تجربة حقلية خلال الموسمين الربيعيين 2012 و 2013 في حقل التجارب التابع لقسم المحاصيل الحقلية-كلية الزراعة-جامعة بغداد. زرعت التجربة في 2012/3/15 و2013/3/13 وحصدت في 2012/6/15 و 2013/6/20 للموسمين بالتتابع. سمدت أرض التجربة في كلا الموسمين بالسماد المركب NPK (18-18-0 بمعدل 540 كغم.هـ -18 دفعة واحدة قبل الزراعة، ثم اضيف سماد اليوريا بمعدل 160

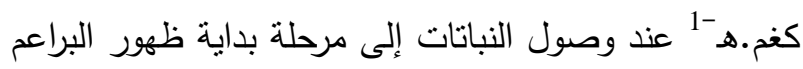
الزهرية (3). زرعت بذور زهرة الثمس صنف اقمار التركيبي

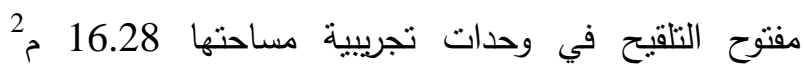
وبكثافة نباتية 55555 نبات.هـ -1، وتركت فواصل بمسافة 5

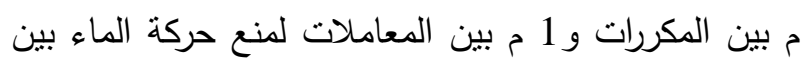
الوحدات التجريبية. تضمنت الوحدة التجربية ستة مروز زرعت على جانب واحد، وبعد اكتمال البزوغ اجريت عملية

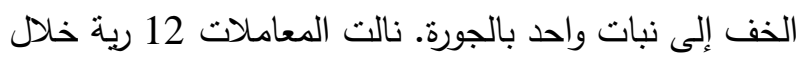
موسم النمو وتمت مكافحة الادغال بالتعشيب يدوياً كلما دعت الحاجة لذلك. استخدم ترتيب الألواح المنشقة بتصميم القطاعات الكاملة المعشاة (RCBD) بثلاثة مكررات، فقد

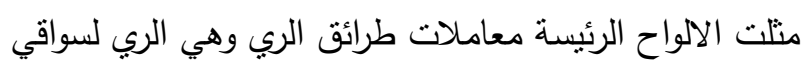

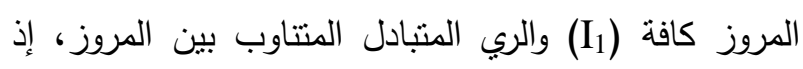
يروى بين ساقية وأخرى بشكل منتاوب (I2) والري المنبادل الثابت، إذ يروى بين ساقية وأخرى بصورة ثابتة (I/3) والري لئني

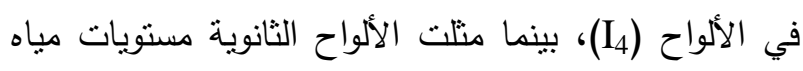

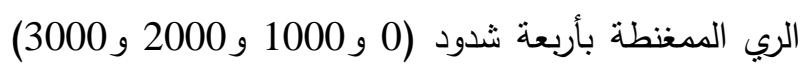
كاوس. تم تحضير الأرض للزراعة على وفق التصميم المستخدم في التجربة للموسمين. تضمنت معاملات طرائق

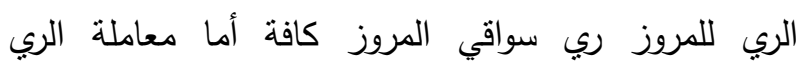
المتتاوب فكان ري المروز الزوجية العدد (6 و 4 و2) بين رية

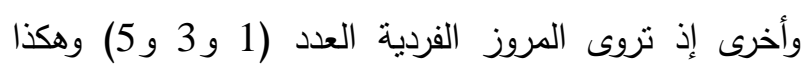
وتنتمر طول مدة نمو المحصول، أما معاملة الري المتتاوب المبرد الثابت ففيها تروي المروز الفردية العدد فقط (1 و 3 و 5) طول مدة نمو المحصول، أما الالواح فقد زرعت بستة خطوط لزوله ايضا لمساحة الوحدة التجريبية نفسها وقد رويت في توقيت التول

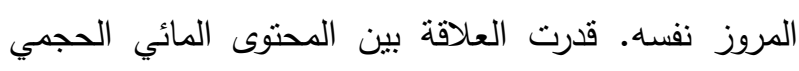

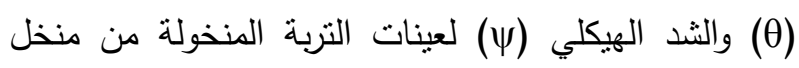




$$
\begin{aligned}
& W U E=\frac{G Y}{W A}
\end{aligned}
$$

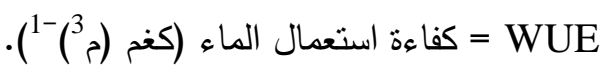

$$
\begin{aligned}
& \text { = GY } \\
& \text { = WA }
\end{aligned}
$$

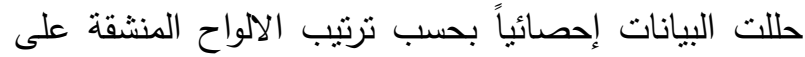
وفق تصميم RCBD وتمت مقارنة المتوسطات الحسابية للمعاملات باستخدام اقل فرق معنوي (LSD) على مستوى

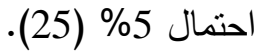

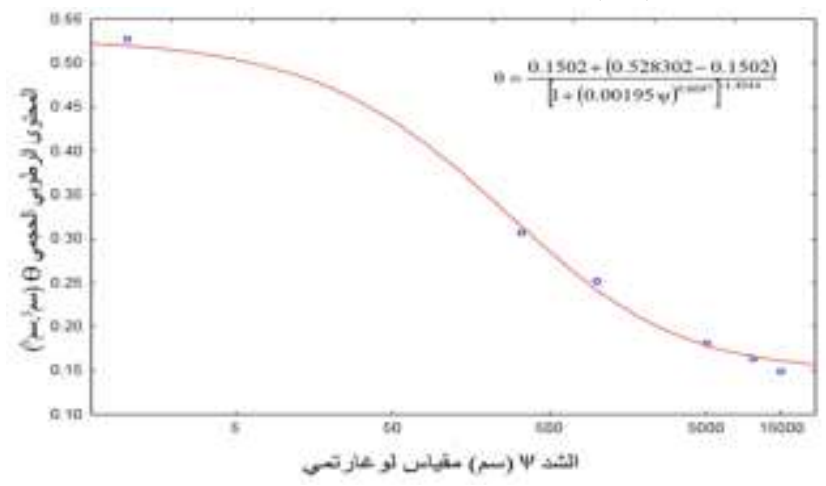

شكل 1. منحنى الوصف الرطوبي للتربة المستخدمة في

$$
\text { الاراسة }
$$

\begin{tabular}{|c|c|c|c|c|c|}
\hline \multicolumn{6}{|c|}{ الريبيعين 2012 و2013 } \\
\hline الاستئهلاك & موسمّم الامطار & ملم مضقاف & كمية المساء & الريات & الري \\
\hline 425 & \multirow{4}{*}{5} & 420 & 4167 & 12 & $\mathbf{I}_{1}$ \\
\hline 255 & & 250 & 2539 & 12 & $\mathbf{I}_{2}$ \\
\hline 255 & & 250 & 2539 & 12 & $\mathbf{I}_{3}$ \\
\hline 425 & & 420 & 4167 & 12 & $\mathbf{I}_{4}$ \\
\hline \multicolumn{6}{|c|}{ الموسم الربيعي 2013} \\
\hline 364 & \multirow{4}{*}{23.8} & 340 & 3389 & 12 & $\mathbf{I}_{1}$ \\
\hline 234 & & 210 & 2065 & 12 & $\mathbf{I}_{2}$ \\
\hline 234 & & 210 & 2065 & 12 & $\mathbf{I}_{3}$ \\
\hline 364 & & 340 & 3389 & 12 & $I_{4}$ \\
\hline
\end{tabular}

جدول 1. كمية الماء المستعمل وعدد الريات والاستهلاك المائي لمحصول زهرة الثمس لطرائق الري للموسمين النتائج والمناقثة الوزن الجاف للمجموع الجذري تبين نتائج جدول 2 أن لمعاملات الري نأنثيرا معنويا في الوزن إندي الجاف للمجموع الجذري، فقد اعطت معاملة الري متوسط لهذه الصفة بلغ 34.08 و 33.88 غم نبات -1 وبنسبة اعنة

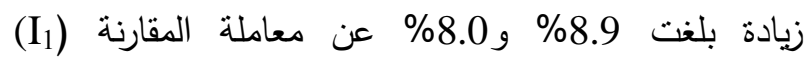

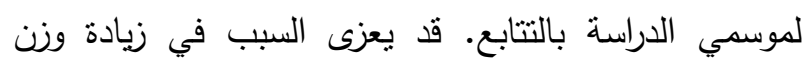

PW ${ }^{\mathrm{Fc}}$ عند السعة الحقلية (بعد الري). = PW ${ }^{w}$ = D وتم حساب الرطوبة الحجمية التي يكون عندها الري بحسب لترب المعادلة الأتية: - ابة

\section{$Q v=Q w \times \partial b$}

إذ أن: Qv= المحتوى الرطوبي على أساس الحجم. = Qw Db الصفات المدروسة 1- الوزن الجاف للمجموع الجذري (غم.نبات -1): استخرج المجموع الجذري بطريقة الاسطوانة المشار اليها من قبل اليل Boham (4) وذللك باستعمال اسطوانة ذات 20 سم قطراً وبارتفاع 50 سم، إذ غرست في التربة لعمق الاسطوانة

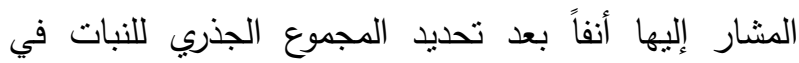
منتصف الاسطوانة، واستخرج المجموع الجذري مع التربة ثم بثان غسل بالماء الاعتيادي وجفف هوائيا حتى ثبات الوزن. 2- ارتفاع النبات (سم): تم قياسه ابتداء من سطح التربة

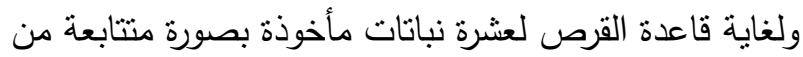
الخطين الوسطين لكل وحدة تجريبية في مرحلة التزهير . 3- قطر الساق (ملم): تم قياسه عند منتصف النبات بجهاز .(Vernier) 4- عدد الأورلق (ورقة نبات -1): حسب منتوسط عدد الأوراق لعشرة نباتات منتابعة من الخطين الوسطيين. 5- المساحة الورقية (سم²): حسبت من المعادلة الاتية x مجموع مربعات العرض x أقصى عرض لأوراق النبات ) .(7) $(0.65$ 6- الوزن الجاف الكلي (غم نبات -1): حسب من متوسط

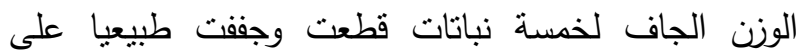
الهواء مع مراعاة تقليبها لحين ثبات الوزن.

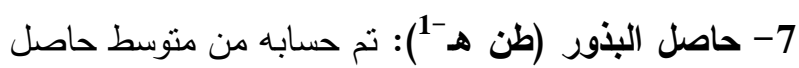
عشرة نباتات متتابعة من الخطوط الوسطية لكل وحدة تجريبية وضرب بالكثافة النباتية.

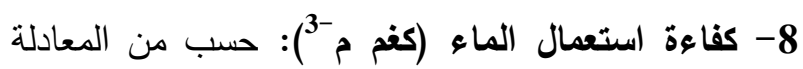

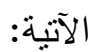


أسلوب الري المتبادل المتغير ذو تأثثر مقارب من ري المروز

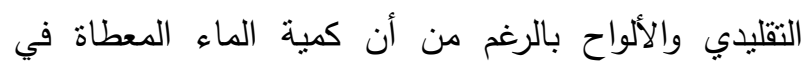

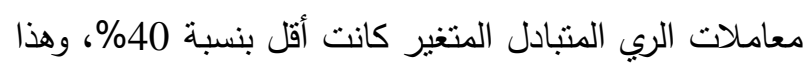

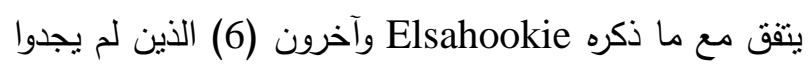
اختلافا معنويا بين الري المتبادل والري الكامل في منوسط ارتفاع نبات زهرة الثمس. يوضح جدول 3 وجود نأثنير معنوي لمعاملات مغنطة مياه الري في متوسط ارتفاع نبات التهات

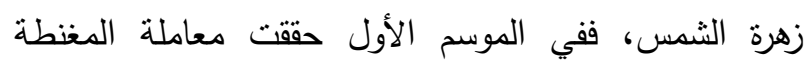
3000 كاوس أعلى متوسط لارتفاع النبات بلغ 170.3 سم الاول لكنها لم تختلف معنويا عن معاملة المغنطة 2000 كاوس اعلى لارسط

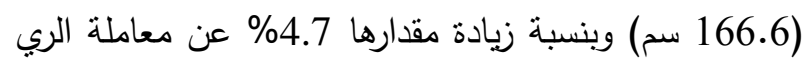
بالمياه الاعتيادية (معاملة القياس) التي حققت أدنى متوسط لادياد لارتفاع النبات بلغ 162.7 سم، أما بالنسبة للموسم الثاني فقداديه

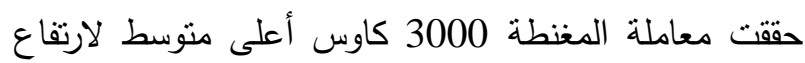

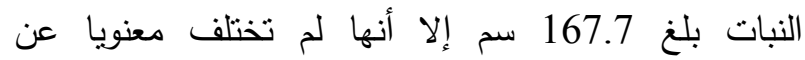
المعاملتين 2000 و 1000 كاوس اللتين حققتا 165.1 و 164.1 سم وبنسبة زيادة تتراوح بين 3\% و و 5.3\% للثدود بين 1000 و 3000 كاوس بالتتابع مقارنة بمعاملة القياس (من دون مغنطة) التي حققت أدنى متوسط لارتفاع النبات بلغ 159.4 سم. جدول 3. تأثير طرائق الري ومغنطة مياه الري في متوسط ارتفاع النبات (سم) للموسمين الربيعيين 2012 و 2013

\begin{tabular}{|c|c|c|c|c|c|}
\hline \multicolumn{6}{|c|}{ الموسم الربيعي 2012} \\
\hline \multirow{2}{*}{ المتوسط } & \multicolumn{4}{|c|}{ مغنطة مياه الري (كاوس) } & \multirow{2}{*}{ طرائق الري } \\
\hline & 3000 & 2000 & 1000 & $\mathbf{0}$ & \\
\hline 167.6 & 171.3 & 165.7 & 167.7 & 165.7 & $\mathbf{I}_{1}$ \\
\hline 165.0 & 170.7 & 167.3 & 162.7 & 159.3 & $\mathbf{I}_{2}$ \\
\hline 164.5 & 168.7 & 166.3 & 162.2 & 160.9 & $\mathbf{I}_{3}$ \\
\hline 167.2 & 170.7 & 167.0 & 166.0 & 165.0 & $I_{4}$ \\
\hline \multirow[t]{3}{*}{ N.S } & \multicolumn{4}{|c|}{ N.S } & أ.ف.م 0.05 \\
\hline & 170.3 & 166.6 & 164.6 & 162.7 & المتوسط \\
\hline & \multicolumn{4}{|c|}{4.3} & أ.ف.م 0.05 \\
\hline \multicolumn{6}{|c|}{ الموسم الربيعي 2013} \\
\hline \multirow{2}{*}{ المتوسط } & \multicolumn{4}{|c|}{ مغتطة مياه الري (كاوس) } & ط ائة الـ قع \\
\hline & 3000 & 2000 & 1000 & $\mathbf{0}$ & طراقى الري \\
\hline 165.3 & 168.7 & 166.9 & 166.9 & 158.8 & $\mathbf{I}_{1}$ \\
\hline 163.9 & 167.8 & 165.2 & 164.4 & 158.3 & $\mathbf{I}_{2}$ \\
\hline 162.4 & 167.1 & 161.7 & 161.1 & 159.6 & $\mathbf{I}_{3}$ \\
\hline 164.7 & 167.4 & 166.5 & 164.2 & 160.8 & $\mathbf{I}_{4}$ \\
\hline \multirow[t]{3}{*}{ N.S } & \multicolumn{4}{|c|}{ N.S } & أ.ف.م 0.05 \\
\hline & 167.7 & 165.1 & 164.1 & 159.4 & المتوسط \\
\hline & \multicolumn{4}{|c|}{3.8} & \\
\hline
\end{tabular}

إن الزيادة في ارتفاع النبات بفعل مغنطة مياه الري قد يكون

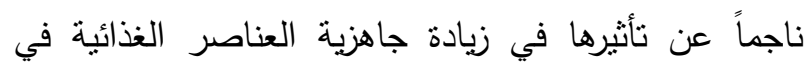
التربة وزيادة كفاءة نقلها وسهولة امتصاصها من قبل خيادة خلايا
الجذر مع قلة كمية المياه المضافة إلى تحفيز الجذور في البحث عن الماء في أعماق أخرى، كما أن قلة الماء تؤدي الجيد إلى زيادة تقرعات الجذور، وهذا يتفق مع ما اثنار إليه إنهاء Geetha زهرة الثمس من أن طول الجذر وحجمه يزداد مع الثد الرطوبي الذي يتعرض له النبات. يبين جدول 2 وجود تأثنير

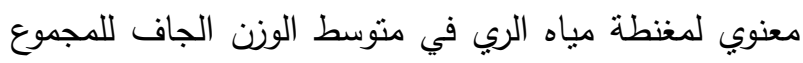

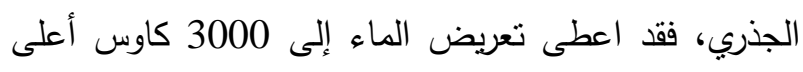

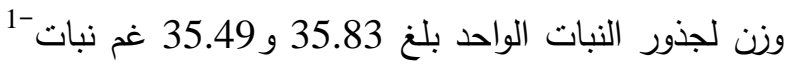
بزيادة مقدارها 36.4\% و 19.5\% للموسمين بالتتابع، ولم يكن هناك فرق معنوي بين معاملتي 2000 و 3000 كادة كأس في في

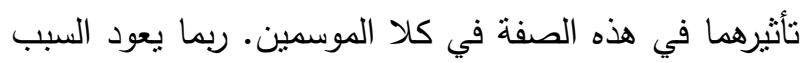
في زيادة وزن الجذور إلى أن الري بالمياه المعالجة مغناطيسيا يزيد من جاهزية العناصر من خلال تكسير بلورات

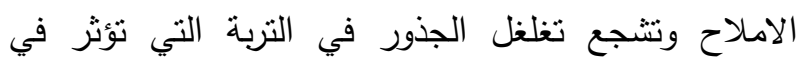

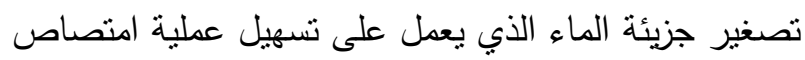

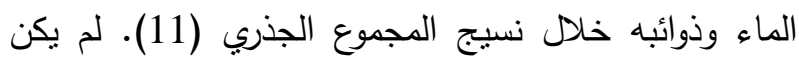
التداخل معنوي بين عاملي الدراسة في متوسط الوزن الجاف للمجموع الجذري ولكلا الموسمين. جدول 2. تأثير طرائق الري ومغنطة مياه الري في متوسط الوزن الجاف للمجموع الجذري (غم نبات

\begin{tabular}{|c|c|c|c|c|c|}
\hline \multicolumn{6}{|c|}{ الموسم الربيعي 2012} \\
\hline \multirow{2}{*}{ المتوسط } & \multicolumn{4}{|c|}{ مغتطة مياه الري (كاوس) } & \multirow{2}{*}{ طرائق الري } \\
\hline & 3000 & 2000 & 1000 & $\mathbf{0}$ & \\
\hline 31.30 & 34.94 & 36.00 & 28.02 & 26.23 & $\mathbf{I}_{1}$ \\
\hline 32.81 & 37.48 & 36.28 & 31.36 & 26.10 & $\mathbf{I}_{2}$ \\
\hline 34.08 & 37.81 & 37.18 & 33.17 & 28.17 & $\mathbf{I}_{3}$ \\
\hline 29.16 & 33.11 & 31.61 & 27.35 & 24.59 & $\mathbf{I}_{4}$ \\
\hline \multirow[t]{3}{*}{0.96} & \multicolumn{4}{|c|}{ N.S } & \multirow{3}{*}{ أ.ف. أمتوسط 0.0505} \\
\hline & 35.83 & 35.27 & 29.97 & 26.27 & \\
\hline & \multicolumn{4}{|c|}{1.09} & \\
\hline \multicolumn{6}{|c|}{ الموسم الربيعي 2013} \\
\hline \multirow{2}{*}{ المتوسط } & \multicolumn{4}{|c|}{ مغتطة مياه الري (كاوس) } & \multirow{2}{*}{ طرائق الري } \\
\hline & 3000 & 2000 & 1000 & $\mathbf{0}$ & \\
\hline 31.37 & 34.88 & 32.58 & 29.07 & 28.93 & $\mathbf{I}_{1}$ \\
\hline 33.73 & 36.55 & 35.03 & 33.21 & 30.13 & $\mathbf{I}_{2}$ \\
\hline 33.88 & 38. 22 & 38.00 & 27.81 & 31.48 & $\mathbf{I}_{3}$ \\
\hline 29.60 & 32.31 & 30.30 & 27.49 & 28.29 & $\mathbf{I}_{\mathbf{4}}$ \\
\hline \multirow[t]{3}{*}{2.32} & \multicolumn{4}{|c|}{ N.S } & أ.ف.م 0.05 \\
\hline & 35.49 & 33.98 & 29.40 & 29.71 & المتوسط \\
\hline & & & & & \\
\hline
\end{tabular}
توضح نتائج جدول 3 عدم وجود تأثير معنوي لطرائق الري

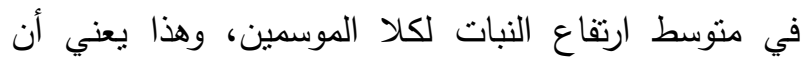


الجذور (17)، وربما يعود السبب إلى أن المياه الممغنطة تؤثز في إعادة انقسام الخلايا وفي زيادة أيض الخلايا

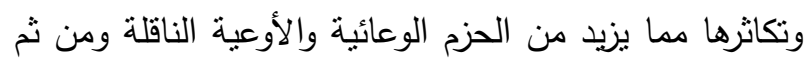
زيادة حجم نسيجي الخشب واللحاء وبذلك يزداد قطر الساق.

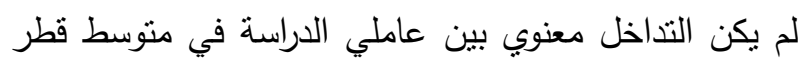

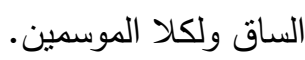
عدد الأوراق تبين نتائج جدول 5 عدم وجود تأثنير معنوي لطرائق الري في متوسط عدد الأوراق لنبات زهرة الثمس ولكلا الموسمين. كما تشير نتائج جدول 5 إلى وجود تأثثر معنوي في متوسط عدد لناد

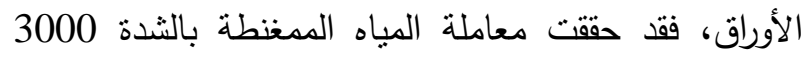
كاوس أعلى منوسط لعدد الاوراق بلغ 31.00 و 28.83 ورقة بلدة نبات-1' ولم تختلف معنويا عن المعاملة 2000 كاوس (30.67 و 28.58) ورقة نبات -1 لكلا الموسمين والمعاملة 1000 كاوس في الموسم الأول فقط (29.58 ورقة نبات ونات وبنسبة زيادة بلغت 7.8\% و 4.3\% عن معاملة القياس التي حققت أدنى منوسط لهذه الصفة بلغ نبات -1 للموسمين بالتتابع. جدول 5. تأثير طرائق الري ومغنطة مياه الري في عدد الأوراق (ورقة نبات -1) للموسمين الربيعيين 2012 و 2013

\begin{tabular}{|c|c|c|c|c|c|}
\hline \multicolumn{6}{|c|}{ الموسم الربيعي 2012} \\
\hline \multirow{2}{*}{ المتوسط } & \multicolumn{4}{|c|}{ مغنطة مياه الري (كاوس) } & \multirow{2}{*}{ طرائق الري } \\
\hline & 3000 & 2000 & 1000 & $\mathbf{0}$ & \\
\hline 30.58 & 32.00 & 30.67 & 30.33 & 29.33 & $\mathbf{I}_{\mathbf{1}}$ \\
\hline 29.83 & 30.33 & 30.67 & 30.00 & 28.33 & $\mathbf{I}_{2}$ \\
\hline 28.25 & 26.33 & 30.67 & 28.00 & 28.00 & $\mathbf{I}_{3}$ \\
\hline 30.33 & 31.33 & 30.67 & 30.00 & 29.33 & $\mathbf{I}_{4}$ \\
\hline \multirow[t]{3}{*}{ N.S } & \multicolumn{4}{|c|}{ N.S } & أ.ف.م 0.05 \\
\hline & 31.00 & 30.67 & 29.58 & 28.75 & المتوسط \\
\hline & \multicolumn{4}{|c|}{1.53} & أ.ف.م 0.05 \\
\hline \multicolumn{6}{|c|}{ الموسم الربيعي 2013} \\
\hline \multirow{2}{*}{ المتوسط } & \multicolumn{4}{|c|}{ مغنطة مياه الري (كاوس) } & \\
\hline & 3000 & 2000 & 1000 & $\mathbf{0}$ & صراتى الري \\
\hline 28.75 & 30.00 & 29.00 & 28.00 & 28.00 & $\mathbf{I}_{1}$ \\
\hline 28.75 & 29.00 & 29.33 & 28.33 & 28.33 & $\mathbf{I}_{2}$ \\
\hline 27.25 & 28.00 & 27.67 & 27.33 & 26.00 & $\mathbf{I}_{3}$ \\
\hline 28.83 & 28.33 & 28.33 & 28.33 & 26.33 & $\mathbf{I}_{4}$ \\
\hline \multirow[t]{3}{*}{ N.S } & \multicolumn{4}{|c|}{ N.S } & أ.ف.م 0.05 \\
\hline & 28.83 & 28.58 & 28.00 & 27.17 & المتوسط \\
\hline & \multicolumn{4}{|c|}{0.65} & \\
\hline
\end{tabular}

ربما يعود سبب ذلك إلى أن تعريض النباتات للمجال المغناطيسي قد يسبب تأثثرات حيوية مختلفة في الأنسجة الخلوية والأعضاء النباتية (17). لم يكن التداخل معنوي بين عاملي الدراسة في متوسط عدد الأوراق في النبات ولكلا الموسمبن
الجذور، فضلاً عن أن الثند السطحي للماء المدغنط يقل عما

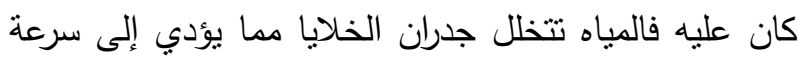
انقسام الخلايا في مناطق النمو في النبات (17)، وهذا يتفق مع وجده Irhem (12) عند استخدام تقانة مغنطة المياه

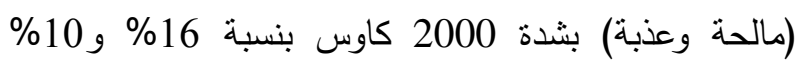

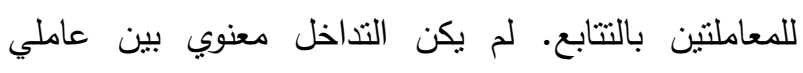
الدراسة في متوسط ارتفاع النبات ولكلا الموسمين.

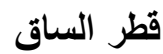
توضح نتائج جدول 4 عدم وجود تأثير معنوي لطرائق الري في منوسط قطر الساق لنبات زهرة الثمس لكلا للموسمين، وهذا يتفق مع ما وجده Nihaba (20) من عدم وجود فروق معنوية بين معاملات الري المختلفة في منتسط قطر ساق نبات زهرة الثمس. كما يوضح الجدول نفسه وجود تأثير معنوي لمعاملات مغنطة مياه الري في متوسط قطر الساق،

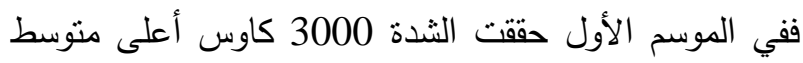
لقطر الساق بلغ 21.30 و 18.86 ملم ولم تختلف معنويا عن الاول الثدة 2000 كاوس التي حققت 20.23 و 18.43 ملم وبزيادة مقدارها 10.2\% و 7.9. \% عن معاملة الري بالمياه الاعتيادية التي حققت أدنى متوسط لقطر الساق بلغ 19.33 و 17.48 ملم للموسمين بالتتابع. جدول 4. تأثير طرائق الري ومغنطة مياه الري في متوسط قطر الساق (ملم) للموسمين الريبعيين 2012 و2013

\begin{tabular}{|c|c|c|c|c|c|}
\hline \multicolumn{6}{|c|}{ الموسم الربيعي 2012} \\
\hline \multirow{2}{*}{ المتوسط } & \multicolumn{4}{|c|}{ مغنطة مياه الري (كاوس) } & \multirow{2}{*}{ طرائق الري } \\
\hline & 3000 & 2000 & 1000 & $\mathbf{0}$ & \\
\hline 20.85 & 22.63 & 21.66 & 19.40 & 19.70 & $\mathbf{I}_{1}$ \\
\hline 20.41 & 21.70 & 19.73 & 20.87 & 19.33 & $\mathbf{I}_{2}$ \\
\hline 19.12 & 19.55 & 18.67 & 19.62 & 18.64 & $\mathbf{I}_{3}$ \\
\hline 20.33 & 19.67 & 19.47 & 20.87 & 21.33 & $\mathbf{I}_{4}$ \\
\hline \multirow[t]{3}{*}{ N.S } & \multicolumn{4}{|c|}{ N.S } & أ.ف.م 0.05 \\
\hline & 21.30 & 20.23 & 19.84 & 19.33 & المتوسط \\
\hline & \multicolumn{4}{|c|}{1.33} & أ.ف.م 0.05 \\
\hline \multicolumn{6}{|c|}{ الموسم الربيعي 2013} \\
\hline \multirow{2}{*}{ المتوسط } & \multicolumn{4}{|c|}{ مغنظة مياه الري (كاوس) } & \\
\hline & 3000 & 2000 & 1000 & $\mathbf{0}$ & لراتى الري \\
\hline 18.72 & 19.55 & 18.79 & 18.73 & 17.80 & $\mathbf{I}_{1}$ \\
\hline 17.95 & 18.93 & 18.21 & 17.27 & 17.39 & $\mathbf{I}_{2}$ \\
\hline 17.72 & 18.01 & 18.07 & 17.33 & 17.46 & $\mathbf{I}_{3}$ \\
\hline 18.14 & 18.97 & 18.67 & 17.67 & 17.28 & $\mathbf{I}_{4}$ \\
\hline \multirow[t]{3}{*}{ N.S } & \multicolumn{4}{|c|}{ N.S } & أ.ف.م 0.05 \\
\hline & 18.86 & 18.43 & 17.75 & 17.48 & المتوسط \\
\hline & \multicolumn{4}{|c|}{0.81} & \\
\hline
\end{tabular}

إن الزيادة في قطر الساق بفعل مغنطة مياه الري قد يكون

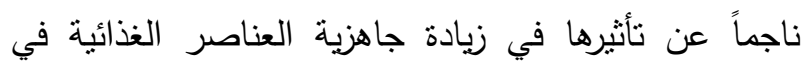
التربة وزيادة كفاءة نقلها وسهولة امتصاصها من فيادة خلايا 
سم²، بينما حققت معاملة الري II مع الثدة 0 كاوس أقل

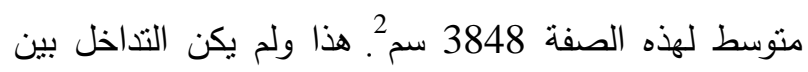
عاملي الدراسة معنويا في الموسم الأول.

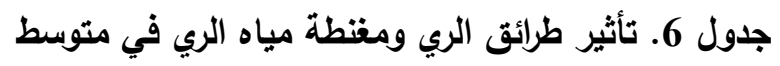
المساحة الورقية للنبات (سم²) للموسمين الريبعيين 2012

\section{و2013}

\begin{tabular}{|c|c|c|c|c|c|}
\hline \multicolumn{6}{|c|}{ الموسم الربيعي 2012} \\
\hline \multirow{2}{*}{ المتوسط } & \multicolumn{4}{|c|}{ مغنطة مياه الري (كاوس) } & \multirow{2}{*}{ طرائق الري } \\
\hline & 3000 & 2000 & 1000 & 0 & \\
\hline 4761 & 5357 & 5144 & 4531 & 4012 & $\mathbf{I}_{1}$ \\
\hline 4648 & 4966 & 5024 & 4627 & 3974 & $\mathbf{I}_{2}$ \\
\hline 4667 & 4897 & 4898 & 4569 & 4304 & $\mathbf{I}_{3}$ \\
\hline 4666 & 5005 & 4925 & 4731 & 4003 & $\mathbf{I}_{4}$ \\
\hline \multirow[t]{3}{*}{ N.S } & \multicolumn{4}{|c|}{ N.S } & أ.ف.م 0.05 \\
\hline & 5056 & 4998 & 4614 & 4073 & المتوسط \\
\hline & \multicolumn{4}{|c|}{244} & أ.ف.م 0.05 \\
\hline \multicolumn{6}{|c|}{ الموسم الربيعي 2013} \\
\hline \multirow{2}{*}{ المتوسط } & \multicolumn{4}{|c|}{ مغتطة مياه الري (كاوس) } & b \\
\hline & 3000 & 2000 & 1000 & $\mathbf{0}$ & صراتى الري \\
\hline 4483 & 4836 & 4399 & 4851 & 3848 & $\mathbf{I}_{1}$ \\
\hline 4325 & 4934 & 4319 & 4068 & 3981 & $\mathbf{I}_{2}$ \\
\hline 4294 & 4933 & 4318 & 4078 & 3849 & $\mathbf{I}_{3}$ \\
\hline 4477 & 4831 & 4393 & 4830 & 3855 & $\mathbf{I}_{4}$ \\
\hline \multirow[t]{3}{*}{ N.S } & \multicolumn{4}{|c|}{402} & أ.ف.م 0.05 \\
\hline & 4883 & 4357 & 4456 & 3883 & المتوسط \\
\hline & \multicolumn{4}{|c|}{211} & \\
\hline
\end{tabular}

الوزن الجاف الكلي

هو صافي إنتاج عمليات التمثيل الكربوني والتتفس والعناصر الغذائية الممتصة، كما يعبر الوزن الجاف للنبات عن كمية

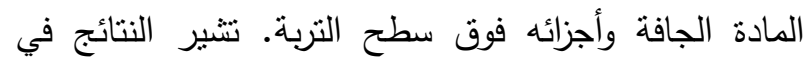

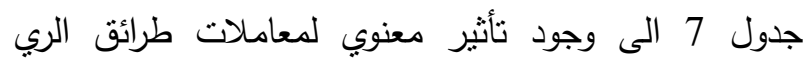
ولتقانة مغنطة المياه في متوسط الوزن الجاف الكلي لنبات زهرة الثمس ولكلا الموسمين، ولم يكن للتناخل بين عاملي فئي الدراسة تأثنير معنوي لكلا الموسمين. تنين نتائج جدول 7 أن لمعاملات الري تأثنرا معنويا في منوسط الوزن الجاف الكلي

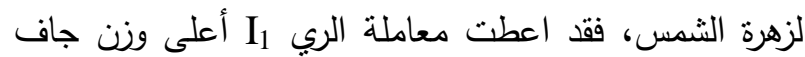
بلغ 157.4 و 154.8 غم نبات-1 ولكنها لم تختلف معنويا عن معاملة ري الألواح (IL) التي اعطت 156.4 و 154.3 غم نبات-1 ومعاملة الري التبادلي المتغير (I2) التي اعطت التماح 156.2 و 153.8 غم نبات -1، بينما اعطى الري التبادلي التئي الثابت (I3) أقل منوسط لهذه الصفة بلغ 145.1 و 148.7

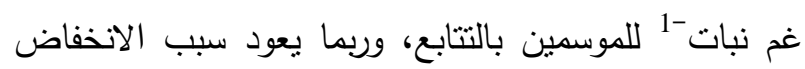

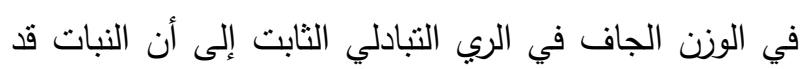

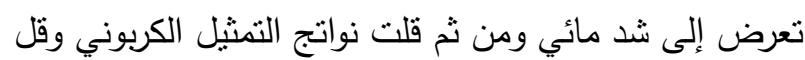

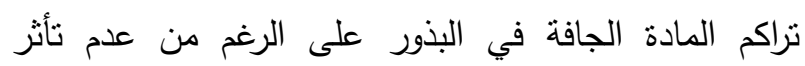

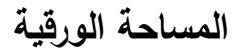

يشير جدول 6 إلى عدم وجود تأثير معنوي لمعاملات طرائق

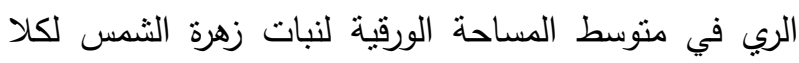

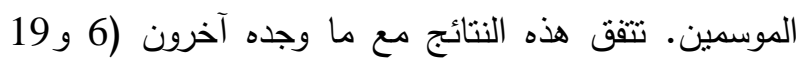
و20) من عدم وجود فروق معنوية بين معاملات الري لهات المختلفة في متوسط المساحة الورقية لنبات زهرة الثمس، وربما يعود السبب إلى ان ري المروز التبادلي يعرض النبات

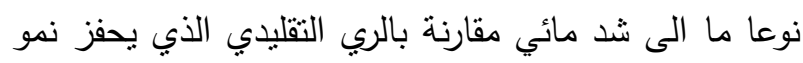
الجذور ويزيد من كثافتها في التربة مما يحسن مقدرة النبات في استخلاص كميات أكبر من رطوبة التربة ومغذياتها (15). يوضح جدول 6 وجود تأثثر معنوي لنقانة مغنطة

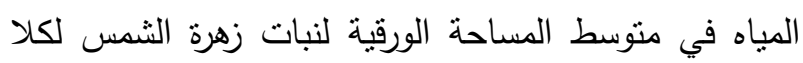
الموسمين، ففي الموسم الاول حققت معاملة الثده 3000 كاوس أعلى متوسط للمساحة الورقية بلغ 5056 سم² والتي لم تختلف معنويا عن معاملة مغنطة المياه بالثدة 2000 كاوس التي حققت منوسط مساحة ورقية بلغ 4998 سم2 2

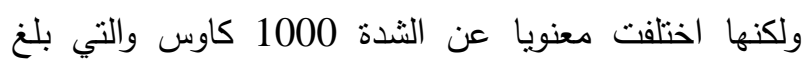
منوسط المساحة الورقية فيها 4614 سم 2 وبنسبة زيادة 24.1 عن معاملة الري بالمياه الاعتيادية التي حققت أقل

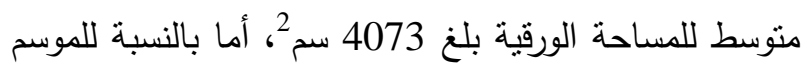
الثاني فقد حققت الثدة 3000 كاوس أعلى متوسط للمساحة

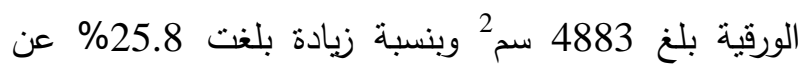
معاملة الري بالمياه الاعتيادية التي حققت أقل متوسط

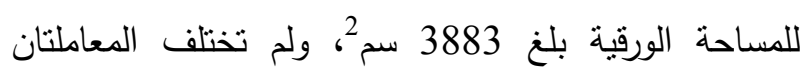

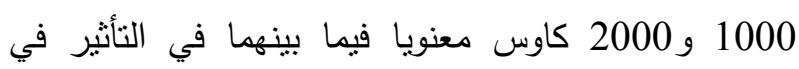

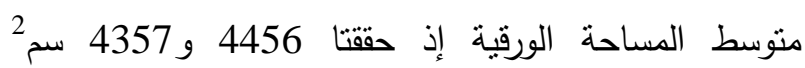
بالتتابع، وقد يعود سبب الزيادة إلى أن المياه الممغنطة تزيد من جاهزية العناصر في التربة وتسهل امتصاصها وانتقالها إلى النبات ومعدل امتصاص النبات للماء ومن ثم تحسين صفات النمو (21). تتفق هذه النتائج مع ما وجده Irhem

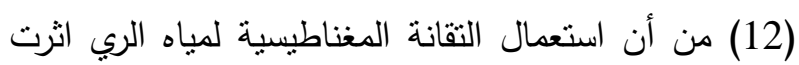
معنوياً في منوسط المساحة الورقية لزهرة الثمس مقارنة بالمياه غير الممغنطة. أما استجابة المساحة الورقية للتداخل بين معاملات طرائق الري ومغنطة مياه الري فقد كان التداخل

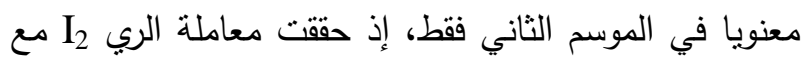
الثدة 3000 كاوس أعلى متوسط لهذه الصفة بلغ 4934 
(جدول 6) ومن ثم زيادة نواتج التمثيل الكربوني وتراكم المادة

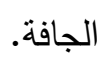
حاصل البذور هي الصفة المهمة التي تمنل خلاصة تأثثر المعاملات المضافة التي تعرض لها النبات. اظهرت نتائج جدول الجدول 8 وجود تأثير معنوي لمعاملات طرائق الري ولتقانة

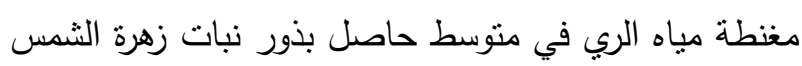

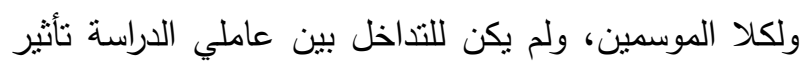

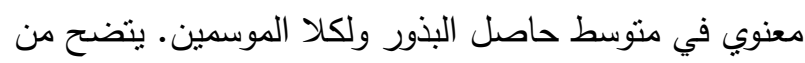
جدول 8 وجود نأثير معنوي لطرائق الري في متوسط حاصل فلونل نبات زهرة الثمس، إذ تفوقت طريقة الري المروز (I1) معنويا بإعطائها أعلى متوسط لحاصل البذور بلغ 3.11 و 2.84 طن هـ -1 لكنها لم تختلف معنويا عن المعاملة Iاعل التي اعطت

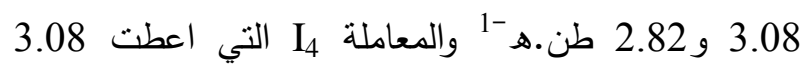
و 2.82 طن.هـ-1 بينما اعطت معاملة ${ }^{-1}$ أقل منوسط وله لحاصل البذور بلغ 2.82 و 2.70 طن هـ -1 لموسمي الدراسة

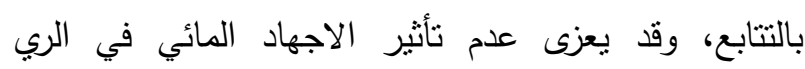

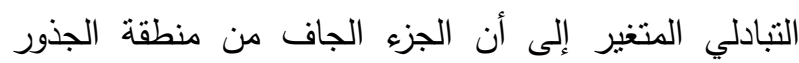
للنبات الذي قطع عنه الماء، سوف يقوم بإرسال اشارات

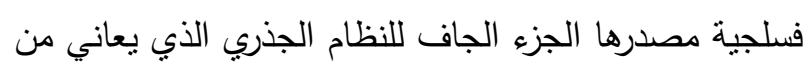
نقص في المحتوى الرطوبي، وهذه الاشارات ناتجة عن التأثثر

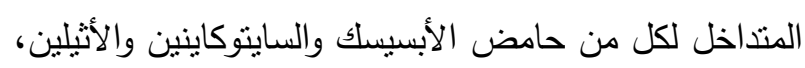

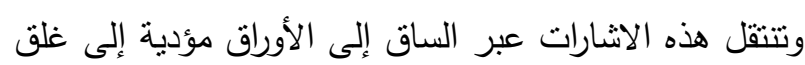

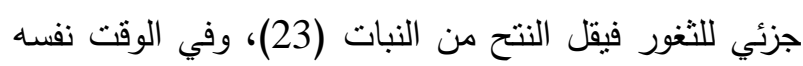
فأن الجزء الأخر من النظام الجذري والمروي سوف يحافظ على امنصاص الماء وبشكل مستمر لتلبية المتطلبات المائية للنبات اللازمة لنمو الجزء الخضري وبكميات مناسبة لتعويض اهن نقص الرطوبة الناتج عن أسلوب التبادل في الري ووجود

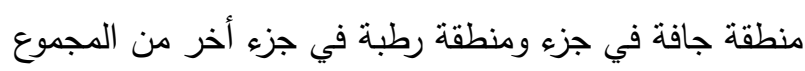

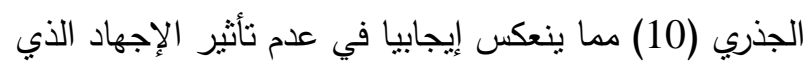

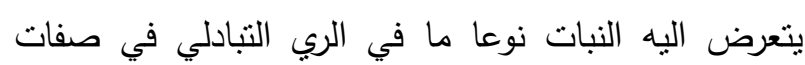

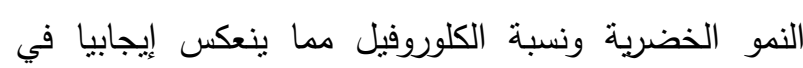
الحاصل. تتفق هذه النتيجة مع ما توصل إليه باحثين آخرين

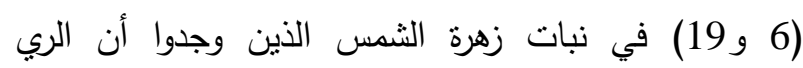

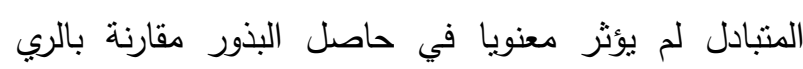

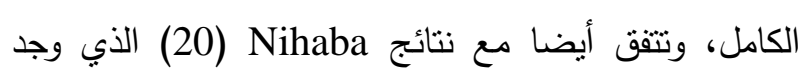

صفات النمو الخضري بسبب انخفاض محتوى الاوراق من الكلورفيل التي تعد المصنع لنواتج التمثيل الكربوني خلال مدة لتهني التزهير في موسمي الدراسة. تتفق هذه النتيجة مع ما ذكره لشان Masoud بين الري الكامل والري التبادلي المتغير في منوسط الوزن الجاف الكلي لنبات زهرة الثمس. كما يوضح جدول 7 وجود تأثنير معنوي لمعاملات مغنطة مياه الري وكانت الزيادة مضطردة مع زيادة شدة المغنطة المستعطلة (1000 و 2000 و3000) كاوس في منوسط الوزن الجاف الكلي لنبات زهرة

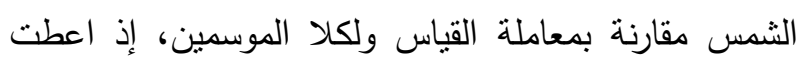

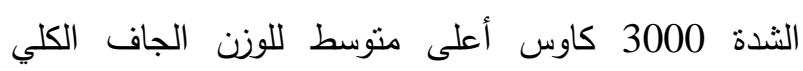
بلغ 173.0 و 169.8 غم نبات -1 واختلفت معنويا عن معاملة الثدة 2000 التي اعطت 1737.0 و 157.0

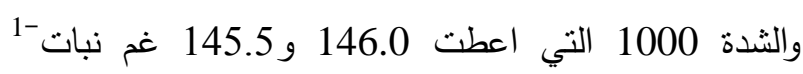
وبنسبة زيادة بلغت 23.97\% و 18.57\% عن معاملة القياس (من دون مغنطة) التي اعطت أدنى منوسط للوزن الجاف الكلي للنبات بلغ 139.2 و 142.5 غم نبات -1 للموسمين بالتتابع. جدول 7. تأثير طرائق الري ومغتطة مياه الري في متوسط الوزن الجاف الكلي (غم نبات -1') للموسمين الربيعيين 2012 و و2013

\begin{tabular}{|c|c|c|c|c|c|}
\hline \multicolumn{6}{|c|}{ الموسم الربيعي 2012} \\
\hline \multirow{2}{*}{ المتوسط } & \multicolumn{4}{|c|}{ مغنطة مياه الري (كاوس) } & \multirow{2}{*}{ طرائق الري } \\
\hline & 3000 & 2000 & 1000 & 0 & \\
\hline 157.4 & 175.7 & 163.4 & 151.1 & 139.5 & $\mathbf{I}_{1}$ \\
\hline 156.2 & 178.0 & 159.3 & 146.4 & 141.1 & $\mathbf{I}_{2}$ \\
\hline 145.1 & 161.1 & 144.6 & 141.9 & 132.8 & $\mathbf{I}_{3}$ \\
\hline 156.4 & 177.1 & 160.7 & 144.6 & 143.3 & $\mathbf{I}_{4}$ \\
\hline \multirow[t]{3}{*}{8.35} & \multicolumn{4}{|c|}{ N.S } & \multirow{3}{*}{ أ.ف. المتوسط 0.0505} \\
\hline & 173.0 & 157.0 & 146.0 & 139.2 & \\
\hline & & & & & \\
\hline \multicolumn{6}{|c|}{ الموسم الربيعي 2013} \\
\hline \multirow{2}{*}{ المتوسط } & \multicolumn{4}{|c|}{ مغنطة مياه الري (كاوس) } & \multirow{2}{*}{ طرائق الري } \\
\hline & 3000 & 2000 & 1000 & $\mathbf{0}$ & \\
\hline 154.8 & 173.3 & 153.0 & 146.3 & 146.5 & $\mathbf{I}_{1}$ \\
\hline 153.1 & 171.6 & 155.8 & 144.1 & 140.8 & $\mathbf{I}_{2}$ \\
\hline 148.7 & 165.3 & 146.6 & 144.7 & 138.3 & $\mathbf{I}_{3}$ \\
\hline 154.3 & 169.0 & 158.7 & 147.0 & 142.6 & $\mathbf{I}_{4}$ \\
\hline \multirow[t]{3}{*}{3.3} & \multicolumn{4}{|c|}{ N.S } & أ.ف.م 0.05 \\
\hline & 169.8 & 153.5 & 145.5 & 142.5 & المتوسط \\
\hline & \multicolumn{4}{|c|}{3.3} & \\
\hline
\end{tabular}

ربما يعود السبب في زيادة الوزن الجاف الكلي إلى دور المغنطة في زيادة جاهزية العناصر وامتصاصها من قبل فيل

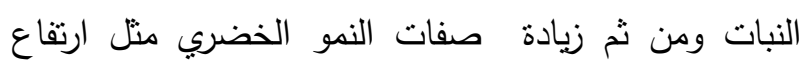
النبات (جدول 3) وعدد الأوراق (جدول 5) والمساحة الورقية 
كفاءة استعمال الماء

يثير الجدول 9 إلى وجود تأثير معنوي لطرائق الري وتقانة

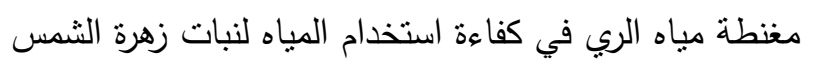
لكلا موسمي الدراسة، ولم يكن للتداخل بين عاملي الدراسة

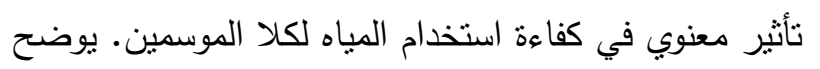
جدول 9 وجود تأثنير معنوي لمعاملات الري في كناءة كفاءة استعمال الماء، فقد تفوقت طريقة الري I2 معنويا بإعطائها

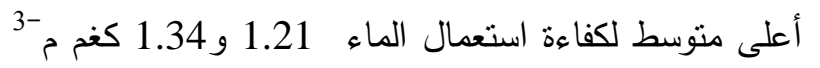

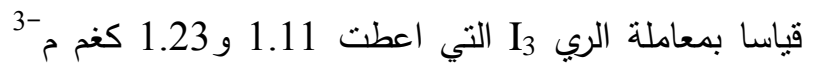
ومعاملة الري I4 التي اعطت أقل منوسط لكفاءة استعمال الماء بلغ 0.73 و0.83 كغم م²3 ولم تختلف معنويا عن المن

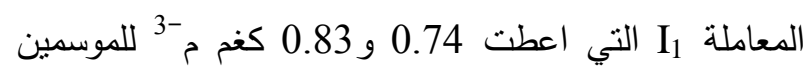
بالتتابع. قد يعزى انخفاض كفاءة استخدام الماء الحقلي عند اعطداء معاملة ري المروز ومعاملة ري الألواح إلى زيادة كمية مياه

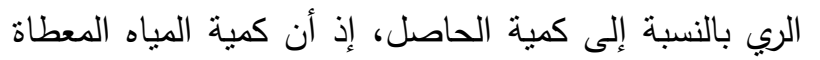
إلى النبات كانت أكبر وبذلك فأن التربة تعرضت إلى إلى غسل إنل للمغذيات والعناصر مما انعكس بشكل سلبي في الحاصل وقلة كفاءة استخدام الماء (18). أما بالنسبة إلى ري المروز التبادلي الثابت والمتغير فقد ادى استخدام 60\% من الماء بالنسبة إلى الحاصل إلى زيادة الكفاءة كون استخدام كميات

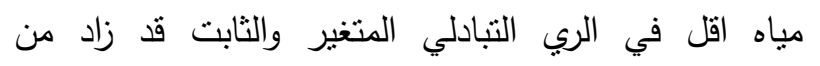
امتصاص العناصر والمغذيات من قبل النبات من التربة وعدم تعرض التربة للغسل في المنطقة القريبة من الجذور

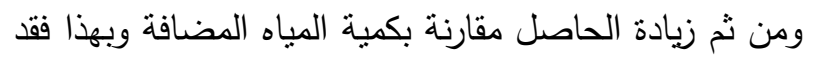

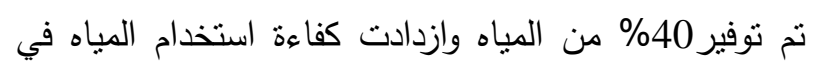

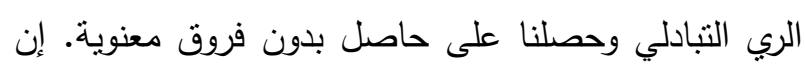

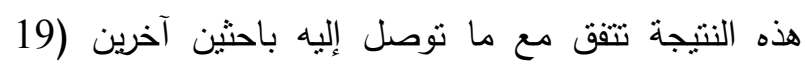
و20) من تفوق الري المتبادل على الري الكامل لنبات زهرة الثمس في كفاءة استعمال الماء. تبين النتائج في جدول 9

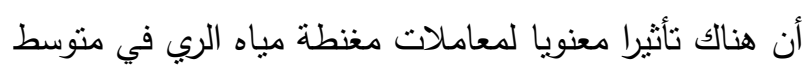

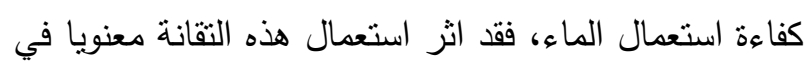

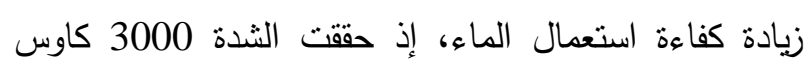
أعلى متوسط لكفاءة استعمال الماء 1.13 و 1.26 كغم م ولم تختلف معنويا عن معاملة مغنطة المياه بالثدة 2000

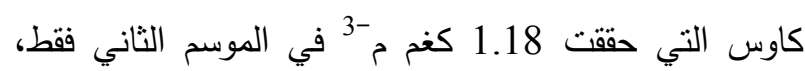

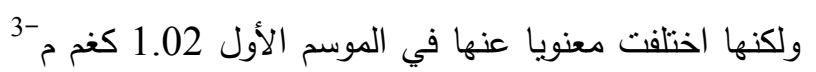

انخفاض حاصل زهرة الثمس في الري التبادلي الثابت مقارنة بطرائق الري الأخرى. كان لمعاملات مغنطة مياه الري تأثنير

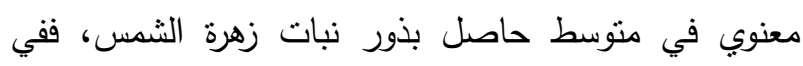

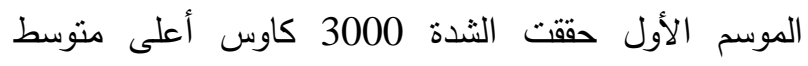
لحاصل بذور بلغ 3.58 طن هـ -1 واختلفت معنويا عن الثندة 2000 كاوس التي بلغ حاصل بذور زهرة الثمس فيها 3.29 طن هـ -1 والثدة 1000 كاوس التي بلغ حاصل بذور زهرة

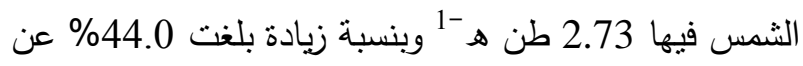
معاملة القياس (من دون مغنطة) والتي حققت أدنى متوسط

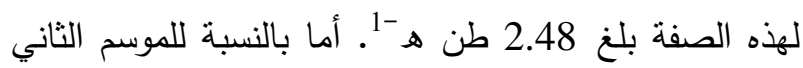
فقد حققت الثدة 3000 كاوس أعلى متوسط لحاصل البذور

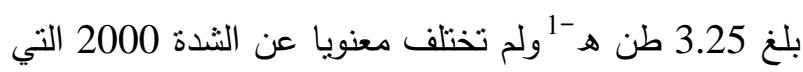

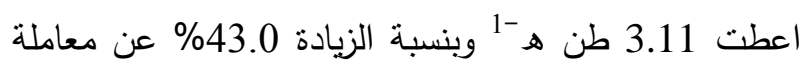
القياس (من دون مغنطة) التي حققت أدنى حاصل بذور بلغ

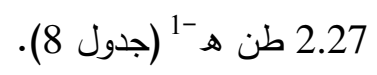
جدول 8. تأثير طرائق الري ومغتطة مياه الري في متوسط حاصل

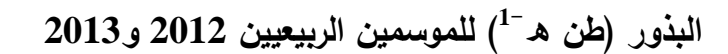

\begin{tabular}{|c|c|c|c|c|c|}
\hline \multicolumn{6}{|c|}{ الموسم الربيعي 2012} \\
\hline \multirow{2}{*}{ المتوسط } & \multicolumn{4}{|c|}{ مغنطة مياه الري (كاوس) } & \multirow{2}{*}{ طرائق الري } \\
\hline & 3000 & 2000 & 1000 & $\mathbf{0}$ & \\
\hline 3.11 & 3.62 & 3.51 & 2.79 & 2.53 & $\mathbf{I}_{\mathbf{1}}$ \\
\hline 3.08 & 3.62 & 3.39 & 2.78 & 2.53 & $\mathbf{I}_{2}$ \\
\hline 2.82 & 3.48 & 2.78 & 2.64 & 3.38 & $\mathbf{I}_{3}$ \\
\hline 3.08 & 3.60 & 3.49 & 2.72 & 2.50 & $\mathbf{I}_{4}$ \\
\hline \multirow[t]{3}{*}{0.10} & \multicolumn{4}{|c|}{ N.S } & أ.ف.م 0.05 \\
\hline & 3.58 & 3.29 & 2.73 & 2.48 & المتوسط \\
\hline & \multicolumn{4}{|c|}{0.21} & أ.ف.م 0.05 \\
\hline \multicolumn{6}{|c|}{ الموسم الربيعي 2013} \\
\hline \multirow{2}{*}{ المتوسط } & \multicolumn{4}{|c|}{ مغتطة مياه الري (كاوس) } & ط ائة الـ \\
\hline & 3000 & 2000 & 1000 & $\mathbf{0}$ & ضراسى الري \\
\hline 2.84 & 3.29 & 3.19 & 2.57 & 2.30 & $\mathbf{I}_{1}$ \\
\hline 2.82 & 3.26 & 3.18 & 2.57 & 2.28 & $\mathbf{I}_{2}$ \\
\hline 2.70 & 3.17 & 2.96 & 2.46 & 2.23 & $\mathbf{I}_{3}$ \\
\hline 2.82 & 3.28 & 3.13 & 2.55 & 2.29 & $\mathbf{I}_{4}$ \\
\hline \multirow[t]{3}{*}{0.05} & \multicolumn{4}{|c|}{ N.S } & أ.ف.م 0.05 \\
\hline & 3.25 & 3.11 & 2.54 & 2.27 & المتوسط \\
\hline & \multicolumn{4}{|c|}{0.21} & \\
\hline
\end{tabular}

ربما يعود السبب في ذللك إلى دور المغنطة في زيادة

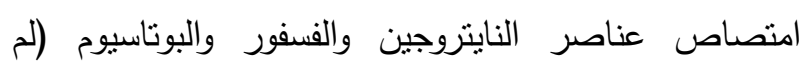
تعرض البيانات) ومن ثم زيادة النمو الجذري والخضري (الجداول 2 و3 و 4 و5 و6 و و7) ومن ثم زيادة العمليات

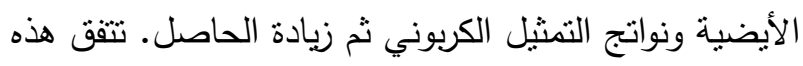
النتائج مع ما حصل عليه Irhem (12) في نبات زهرة الثمس من وجود تأثير معنوي لمغنطة مياه الري في منوسط

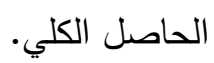


Agricultural Guidance and Cooperation, Ministry of Agriculture. p. 8.

4. Boham, W. 1979. Methods of studying roots systems. Springer Veriang, Berlins Heidelberag, N.Y. USA. pp. 150.

5. Colic, M.; A. Chien and D. Morse. 1998. Synergistic application of chemical and electromagnetic water treatment in corrosion and scale prevention. Croatica Chemica Acta. 71(4): 905-916.

6. Elsahookie, M. M., F. Oraha and A. Humood. 2006. Role of alternative irrigation, father lines for mothers and site in the sunflower performance. Iraqi J. Agric. Sci. 37 (1): 117-122.

7. Elsahookie, M. M.; and E. E. Eldabas. 1982. One leaf dimension to estimate leaf area in sunflower. J. Agron., and Crop Sci. 151: 199204.

8. Geetha, A.; J. Suresh and P. Saidaiah. 2012. Study on response of sunflower (Helianthus annuus L.) genotypes for root and yield characters under water stress. Curr. Bio. Tech. 6(1): 32-41.

9. Hillel, D. 1980. Application of Soil Physics. Academic press. Inc. New York. p. 116-126.

10. Hu, T.; S. Kang; F. Li and J. Zhang. 2011. Effects of partial root-zone irrigation hydraulic conductivity in the soil-root system of maize plants. J. Exp. Bot. 62(12): 4163-4172.

11. Iqbal, N.; M. Y. Ashraf and F. Azam. 2005. Effect of exogenous application of glycinebetaine on capitulum size and achene number of sunflower under water stress. International J. Biol. Biot. 2(3): 765-771.

12. Irhem, H. A. 2009. The Effect of Magnetic Water Quality on Evaporation- transpiration, Growth and Yield of Sunflower (Helianthus annuus L.). M.Sc. Thesis, Coll. of Agric., Univ. of Baghdad. pp. 95.

13. Jadaan, H. J., F. H. Murjana and H. S. AlFalahi. 1999. Analysis of qualitative characteristics of different genotypes of the sunflower seeds. Iraqi J. Agric. Sci. 30(1): 2534.

14. Kanber, R.; S. Önder; M. Ünlü; S. Tekin; M. Sezen and K. Diker. 2012. Different furrow management techniques for cotton production maize production in an arid area. Agri. Water Manage. 45: 267-274.

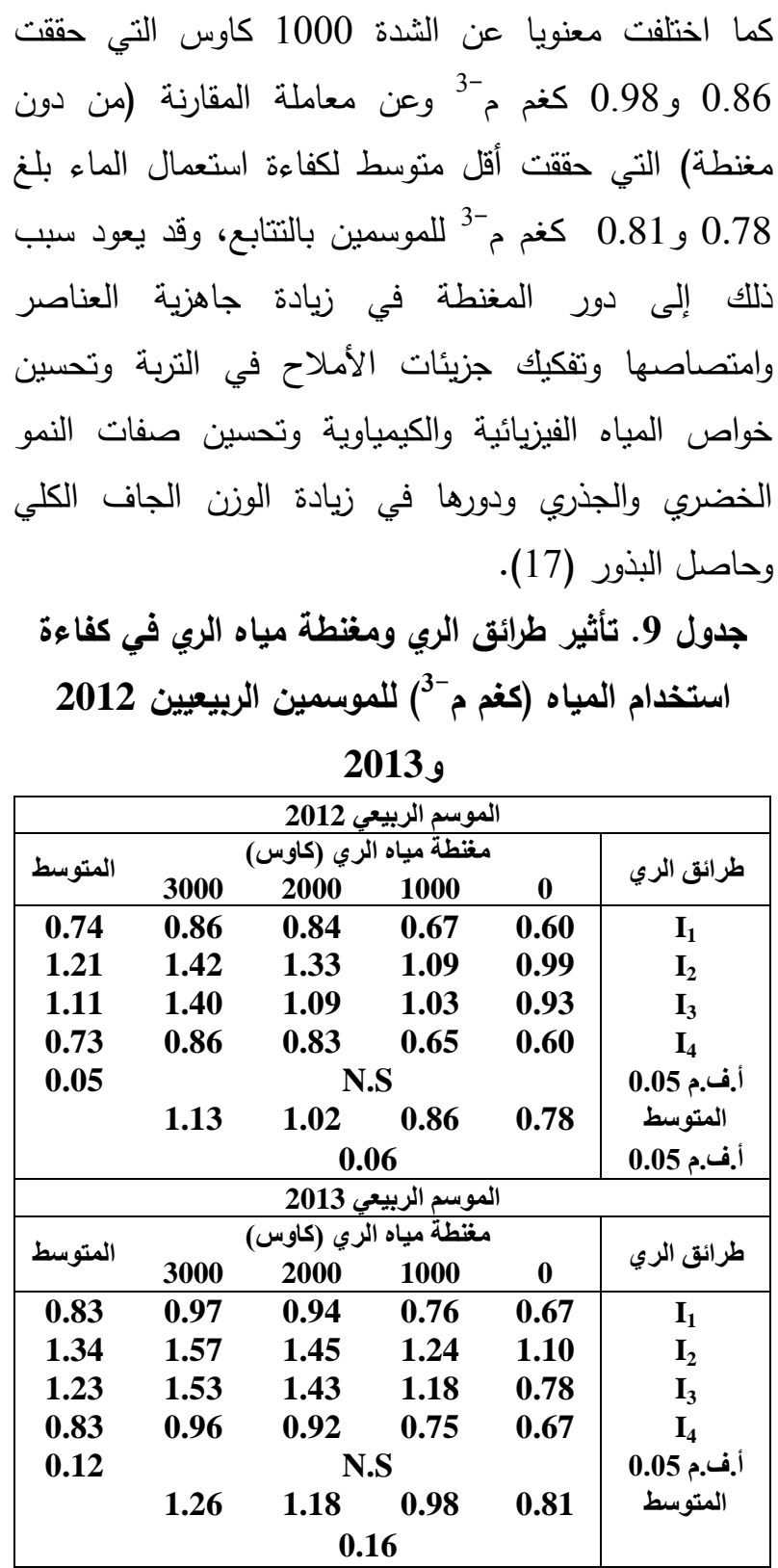

\section{REFERENCES}

1. Abed, H. O. 2007. The reality of water resources and assess the water requirements for irrigated agriculture in Iraq for the period 1980-2001. Karbala Scientific J. 5(4): 24-32.

2. Agele, S. O.; I. O. Maraiyesa and I. A. Adenji. 2007. Effect of variety and row spacing on radiation interception, partitioning of dry matter and seed set efficiency in late season sunflower (Helianthus annuus L.) in a humid zone of Nigeria. Afr. J. Agric. Res. 2(3): 80-88.

3. Al-Rawi, W. M. 2001. Guidance in the Sunflower Cultivation. Public Authority for and water conservation in Harran plain, Şanlıurfa. Turk. J. Agric. 36: 77-94.

15. Kang, S.; Z. Liang; Y. Pan; P. Shi and J. Zhang. 2000. Alternate furrow irrigation for 
magnetic field on water relations in lettuce seeds. II-Experimental results. Bioelectromagnetics. 23(7): 550-552.

22. Sanchez, M. C.; R. Domingo and J. R. Castel. 2010. Review. Deficit irrigation in fruit trees and vines in Spain. Spanish J. Agric. Res. 8(2): 5-20.

23. Schachtman, D. P. and J. Q. D. Goodger. 2008. Chemical root to shoot signaling under drought. Trends in Plant Sci. 13(6): 281-287.

24. Senyigit, U. and F. O. Ozdemir. 2011. Effects of partial root zone drying and conventional deficit irrigation on yield and quality parameters of "Williams Pride" apple cultivar drafted on M9 rootstock. Sci. Res. Essays. 6(17): 3776-3783.

25. Steel, G. D. and J. H. Torrie. 1980. Principles and Procedures of Statistics. Mc Graw. Hill Book Company, Inc. New York, USA. pp. 480.

26. Zein, A. K. 2002. Rapid determination of soil moisture content by the microwave oven drying method. Sudan Engineering Soc. J. 48(40): 43-54.
16. Kohnke, H. 1968. Soil physics. Mc Graw Hill Book Company, Inc. New York, USA. p. 105-108.

17. Kronenberg, K. 2005. Magneto Hydrodynamics: The Effect of Magnets on Fluids GMX International. corporate@ gmxinterhatinal.com.

18. Lehrsch, G. A.; R. E. Sojka and D. T. Westermann. 2001. Furrow irrigation and N management strategies to protect water quality. Commun. Soil Sci. Plant Anal. 32(7\&8): 1029-1050.

19. Masoud, T. K. 2013. Role of Partial Irrigation of Rows and Organic Matter in the Water Requirement, Growth and Yield of sunflower. M.Sc. Thesis, Dept. of Soil Sci., and Water Resources, Coll. of Agric., Univ. of Baghdad. pp. 112.

20. Nihaba, R. S. 2011. Rows alternative irrigation of sunflower in the province of Babylon area. Euphrates J. Agric. Sci. 3(1): 43-48.

21. Reina, F. G.; L. A. Pascual and I. A. Fundora. 2002. Influence of a stationary 